\title{
COMPARATIVE PERFORMANCE STUDY OF GASKETED AND NON-GASKETED FLANGE JOINTS UNDER COMBINED INTERNAL PRESSURE, AXIAL AND BENDING LOADING - AN EXPERIMENTAL STUDY
}

\author{
MUHAMMAD ABID \\ Faculty of Mechanical Engineering, GIK Institute of Engineering Sciences and Technology, \\ Topi, NWFP, Pakistan. \\ abid@giki.edu.pk
}

\begin{abstract}
In this paper result of an extensive comparative experimental study of a gasketed and non-gasketed flange joint with different assemblies with different combined load combinations is carried out to investigate joint performance i.e. joint strength and sealing capability. Actual joint load capacities are determined under both the design and proof test pressure with maximum additional external loading (axial and bending) that can be applied for safe joint performance. In addition, application of combined load is also discussed in the light of equivalent pressure approach.
\end{abstract}

KEYWORDS: Gasketed, Non-gasketed, Joint, Combined, Operating, Axial, Bending, Sealing, Strength

\section{INTRODUCTION}

Different types of flange joints evolved over the centuries and were perfectly adequate for their duties at low pressure and temperature. However, high pressure, temperature and different external loading applications led to their sealing problems. Leakages (small and large) in flange joints, is a continued significant safety concern both in terms of human life, environmental effect and cost. With the rapid advancement in technology for high pressure, high temperature and external loading applications, trends are changing. A flange joint must have adequate mechanical strength and good leak tightness, therefore it is important to evaluate the integrity and sealing performance at actual operating conditions. Available design rules [1,2] for flange joints are mainly concerned with the strength of the flanges and do not sufficiently consider for their sealing. In addition, these do not address the effect of any external loading on integrity and sealing performance. Non-gasketed flange joints are considered as an alternative due to the 'static mode of load' under bolt up and different internal pressure and temperature loading [3-10], providing better joint strength and sealing capabilities. External loading on the gasketed flange joint is discussed in [11-17] but these studies are only for the gasketed flange joints with axial and bending loading in addition to internal pressure. 
Present available design codes only consider internal pressure loading for the design of the flange joints. However, for the past few years, it has been realised that the actual load conditions should be considered for the design of the joints. Regarding this in new European code prEN13445 [18] based on prEN1591-1, for the alternative design method, consideration is also given to the load capacity of the joints for other external loading in addition to the internal pressure. Although the method described is detailed but it consists of complicated equations and need to be explained and fully understood before using it properly for the design of flanges. No consideration is given to the non-gasketed joints for design and applicability even in the recent work. From some reference, it is noted that codes for the non-gasketed joints are in progress, but going through the methodology adopted, it is found that the approach used is the same as for the gasketed joints for design and load capacity calculations.

In this paper result of detailed experimental study is performed to investigate joint's strength and sealing capability under different internal pressure and axial loading and bending loading. The level and distribution of different stress magnitudes and its variation are used to quantify joint strength, whereas joint's sealing behavior is studied from any physical leakage/seepage from the joint during tests.

\section{EXPERIMENTAL PROGRAM}

\subsection{Test rig components selection and calculations}

A gasketed flange joint of size four inch ANSI class 900\# and an equivalent nongasketed flange joint with pipe of schedule 160 and of thickness $13.5 \mathrm{~mm}$ are selected and appropriate test rigs are made. All flange and bolt dimensions, bolt quantity and ratings for the gasketed flange joint are in accordance with ANSI B16.5 [19]. Non-gasketed joint is an emerging design and 16 bolts of M10 diameter are used as per BS3692 [20]. Material properties for the gasketed and non-gasketed flanges, pipes and bolts are as per ASME code, section II, part D [21]. Yield strength of flange and pipe material is 248MPa. Spiral wound gasket is used in the gasketed of make Klinger, whereas O-ring is used in the nongasketed joint.

The reason for selecting this size is its common use, recommendation of the industrial sector and the ease of handling in the laboratory and the tooling needed [4]. For all series of tests gasketed and non-gasketed flanges with and without O-ring used to make joint assembly is shown in Fig. 1. Flanges and pipe were arranged as per specifications recommended by codes and industrial sector. End caps at end of pipe pieces were designed as per PD5500 [22] and remaining calculations for saddle; frame, pin and side-bars were based on general structure design [4]. 


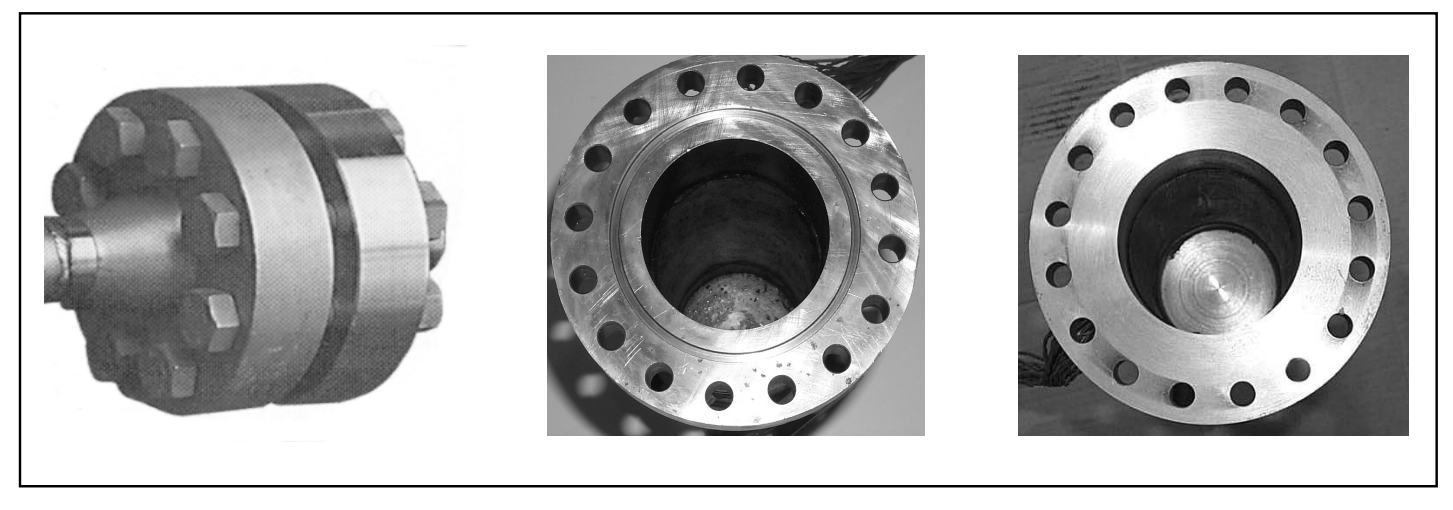

(a)

(b)

(c)

Fig. 1: (a) GJ, (b) NGJ with O-ring groove, (c) Non-gasketed joint without O-ring groove.

\subsection{Strain Gauging and Instrumentation}

To measure strength of test rig comprising of flanges, pipes, and bolts and supporting structure, strain gauges are placed on different locations of importance. Connections are made with data logging system to record results from strain gauges attached at bolts, frame, flange, pipe section, pressure transducer and test machine.

BOLTS: In gasketed joint, four strain gauges of $350 \mathrm{Ohm}$ are placed on the shank at an angle of 90 degree on each bolt and leads are taken out at the top of the bolt head as shown in [Fig.2a]. In non-gasketed joint, two strain gauges of $350 \mathrm{Ohm}$ are placed on shank at an angle of 180 degree on each bolt due to its small diameter and leads are taken out between washer and bolt head as shown in [Fig. 2b]. Quarter bridge circuit is used for strain measurements. Strain gauges are attached on the bolts in order to measure preload applied and its variation during bolt up and operating conditions.

SIDE FRAME: For tests, axial load is applied using hydraulic pump and it is measured from pressure gauge attached on the pump. To measure it accurately in terms of digital or electronic data during the application of different loading it is decided to attach two pairs of strain gauges of $120 \mathrm{Ohm}$ on the frame (free end) side plates that hold the pin [Fig.2c]. Side frame is also calibrated before using for actual tests and applied load was calculated from strain recorded.

FLANGE AND PIPE: Four pairs of strain gauges of $120 \mathrm{Ohm}$ resistance are attached at hub centre and at hub-flange locations at an angle of 90 degree. At hub-flange, intersection strain gauges are attached at the fillet as well as along elliptical portion to note more accurate stress behavior. Four pairs of strain gauges of $120 \mathrm{ohm}$ are attached at an angle of 90 degree at pipe centre away from locations of discontinuity. Strain gauges attached for GJ and NGJ are shown in Fig.2d and Fig.2e respectively. Strain gauges are attached on flange and pipe in order to observe any yielding under bolt up and operating conditions. 


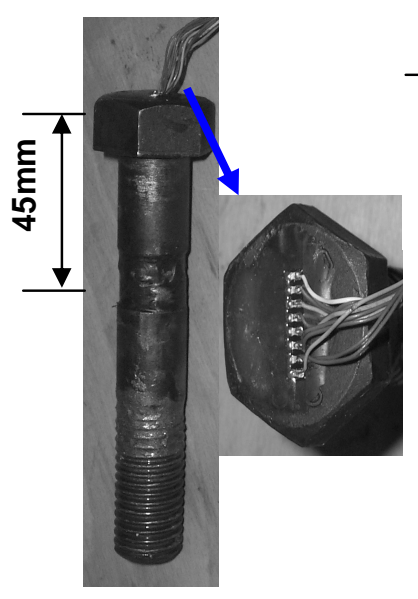

(a)

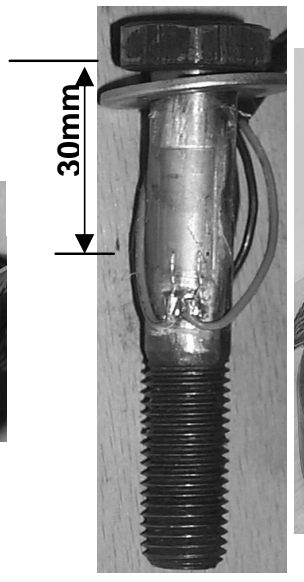

(b)

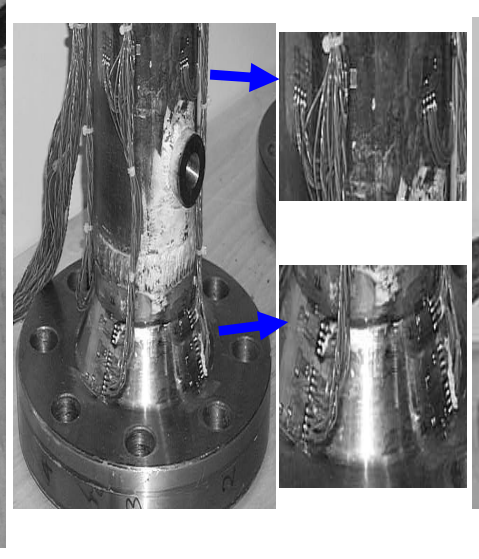

(c)

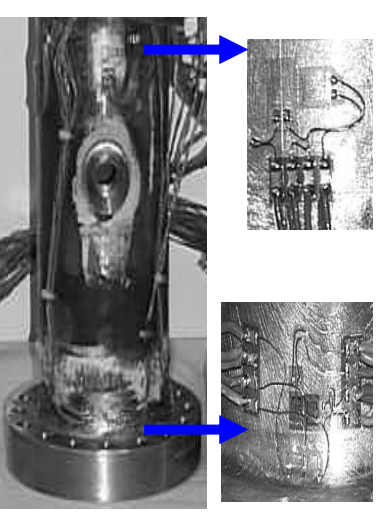

(d)

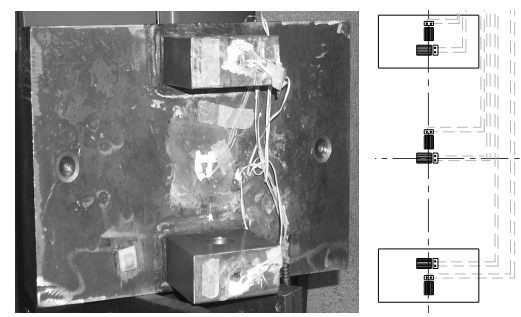

(e)

Fig. 2: Strain gauging of; (a) bolt-GJ, (b) bolt-NGJ, (c) Side frame (d) pipe and flange section-GJ, (e) Pipe and flange section - NGJ.

\subsection{Test Rig Assembly and Testing}

In order to ensure accuracy, calibration of bolts, pressure gauges, pressure transducer, hydraulic pumps, hydraulic pistons, machine for bending load, side frame for axial load and clip gauge for joint opening measurement was performed. Success of the bolted flange joint depends upon its proper assembly using high quality bolts, proper assembly procedure, proper tooling and so on. These factors are very important to ensure a leak proof joint, as each of these can be one of the main causes of the joint failure. Using 'hand-tightening' methodology with the calibrated torque wrench gasketed joint is tightened as per two following sequences;

- Sequence-1 as per sequence mentioned in the ES090 1, 5, 3, 7, 2, 6, 4, 8 [23].

- Sequence-2 as per sequence 1,2,3,4,5,6,7 and 8 .

Gasket manufacturers suggest different bolt torque values to achieve proper gasket seating stress. It is observed that maximum recommended torque applied could only achieve $30 \sim 35 \%$ stress of the yield of bolt material, which is considered very low, hence bolt relaxation and leakage is observed [4]. These load levels avoid gasket crushing, but still cause flange yielding due to flange rotation. 
For the non-gasketed joint, using 'hand-tightening' methodology with extra long handle spanner, sixteen bolts were tightened as per sequence i.e. 1, 9, 5, 13, 3, 11, 7, 15, 2, $10,6,14,4,12,8$, and 16 [4]. Pre-load of up-to $80 \%$ of the yield of the bolt was applied in the bolts of non-gasketed joint.

\subsection{Testing under Combined Loading}

Test rig arrangement for gasketed and non-gasketed joint under combined loading is shown in Fig. 3a and Fig. 3b respectively. Figure 3c shows schematic of the internal pressure, axial and bending loading applied, distance between saddle support and distance between bending loading points. Loading and unloading sequence discussed below are applied as they may happen in the industry during operating conditions.

Gasketed Joint: Three sets of tests were performed by applying first internal pressure, then maintaining this pressure, axial load was applied and finally keeping these two loads, bending was applied. During unloading, first bending, then axial and at the end pressure was removed. Two assemblies were tested during all the tests. At maximum permissible working pressure of $15.3 \mathrm{MPa}$, joint assemblies were tested with a maximum axial load of $525 \mathrm{kN}$ and bending load of $68 \mathrm{kN}$. Tests were also performed at proof test pressure of 23 $\mathrm{MPa}$ in addition to axial applied load of $360 \mathrm{kN}$ and bending of $153 \mathrm{kN}$. Another test was also performed with pressure of $23 \mathrm{MPa}$, axial load of $135 \mathrm{kN}$ with bending load of 158 $\mathrm{kN}$. The joint opening or rotation was measured at the bottom using clip gauge arrangement. The loads were kept for 10 minutes. During unloading first, bending load was removed, then axial and at the end internal pressure. Strains were recorded during loading and unloading and the joint was monitored for any leakage and opening or gap.

Non-gasketed Joint: Test rig arrangement for combined loading is shown in [Fig.3b]. In order to observe joint strength and sealing capabilities, under combined loading, following three sets of tests were performed for two non-gasketed joint assemblies with seal ring inside.

Test 1: Two sets of tests were performed for this load combination. First, an internal pressure up-to $15.3 \mathrm{MPa}$ was applied, and then maintaining this pressure axial load up-to $180 \mathrm{kN}$ was applied. Finally keeping the first two conditions, bending was applied up-to $134 \mathrm{kN}$. The loads were kept for 10 minutes. During unloading first, bending load was removed, then axial and at the end pressure. For the second sequence, first axial load up-to $180 \mathrm{kN}$, secondly maintaining this axial load bending load of $134 \mathrm{kN}$ was applied. Finally maintaining both the loads, internal pressure up-to $15.3 \mathrm{MPa}$ was applied. During unloading, first bending load was removed, then axial and pressure at the end. Strains were recorded during all the loading. The loads applied were in a normal speed as mentioned in section of bending and axial loading. The joint was continuously monitored for any joint opening at the bottom and the leakage. Results are discussed in the next sections.

Test 2: During this test, during loading the same sequence was adopted as mentioned in test 1 , whereas during unloading first axial load, then bending and at the end internal pressure applied was removed. A pressure of $23 \mathrm{MPa}$ was applied with axial load up-to $180 \mathrm{kN}$ and then bending to $68 \mathrm{kN}$. Strains were recorded during loading and unloading and the joint was monitored for any leakage and opening or gap. 
Test 3: This test was performed with the maximum loading conditions. During loading first an axial load of $335 \mathrm{kN}$, followed by a bending of $103 \mathrm{kN}$ was applied. Finally, internal pressure was applied up-to the proof test pressure of $23 \mathrm{MPa}$. Strains were recorded during loading and unloading and the joint was monitored for any leakage and opening or gap.

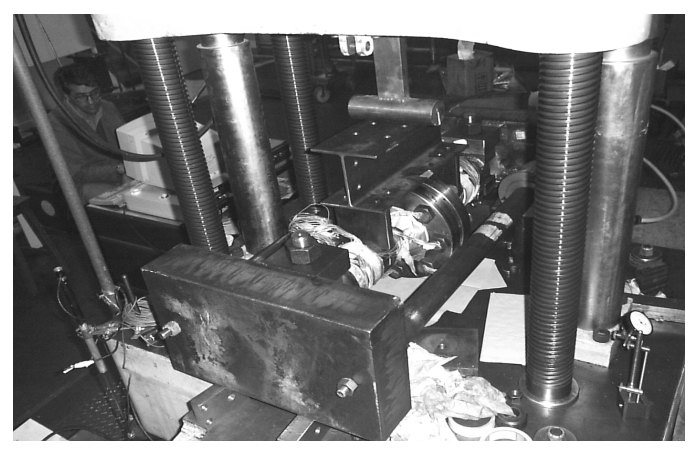

(a)

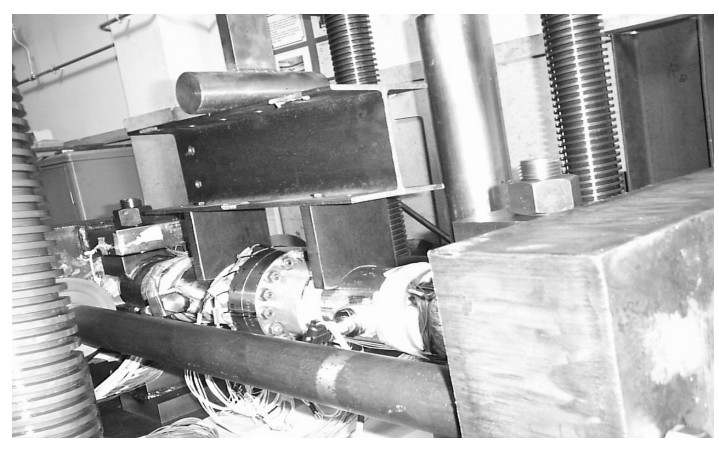

(b)

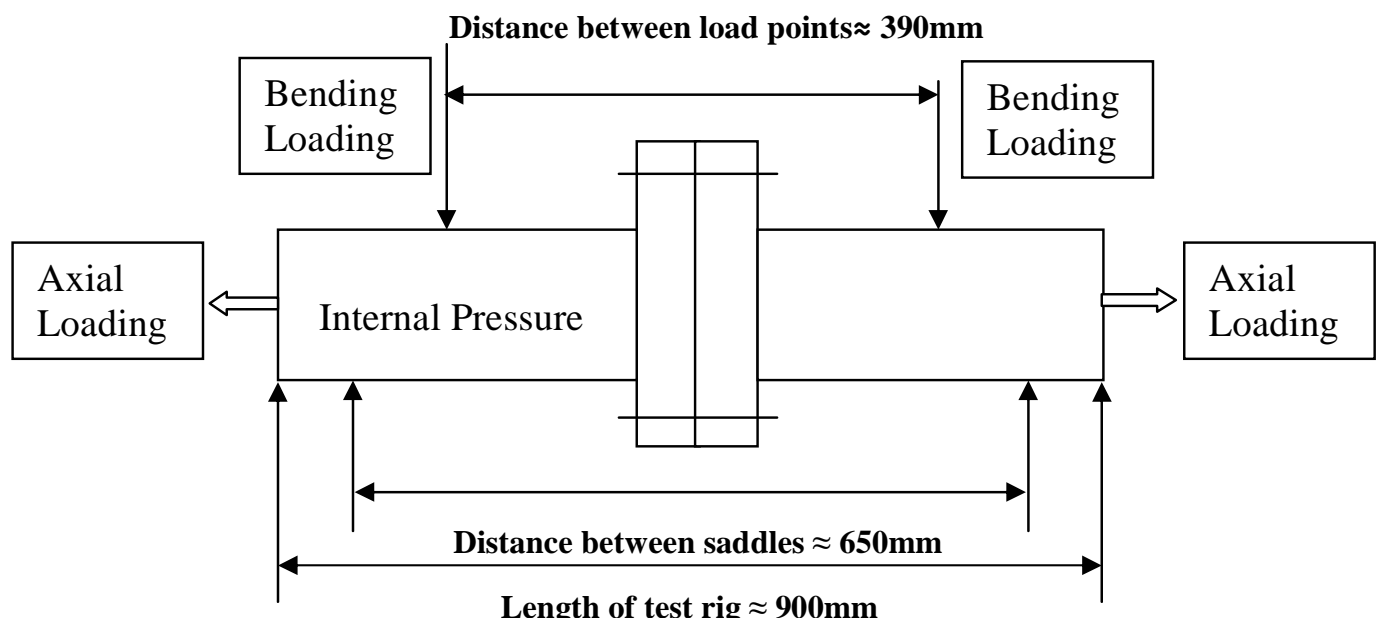

(c)

Fig. 3: Arrangement for combined loading: (a) GJ, (b) NGJ (c) Joint assembly showing distance between load applied, saddles and overall length. 


\section{RESULTS AND DISCUSSION}

\subsection{Stress Calculations from Experimentally Measured Strains and Strain Measurement Locations}

Two strain gauges were attached at each location i.e. in axial and hoop direction. Stresses calculated from experimental strains recorded at various strain-gauge locations during bolt up and operating conditions were converted to principle stresses both in the axial and hoop directions using following expressions given in equation 1 and 2 [24].

$$
\begin{aligned}
& \sigma_{1}=\frac{E}{1-v^{2}}\left(\varepsilon_{1}+v \varepsilon_{2}\right) \\
& \sigma_{2}=\frac{E}{1-v^{2}}\left(\varepsilon_{2}+v \varepsilon_{1}\right)
\end{aligned}
$$

Location of strains measured at flange and pipe is shown in Fig. 4a and for bolts of gasketed and non-gasketed joints as shown in Fig. 4b and Fig. 4c.

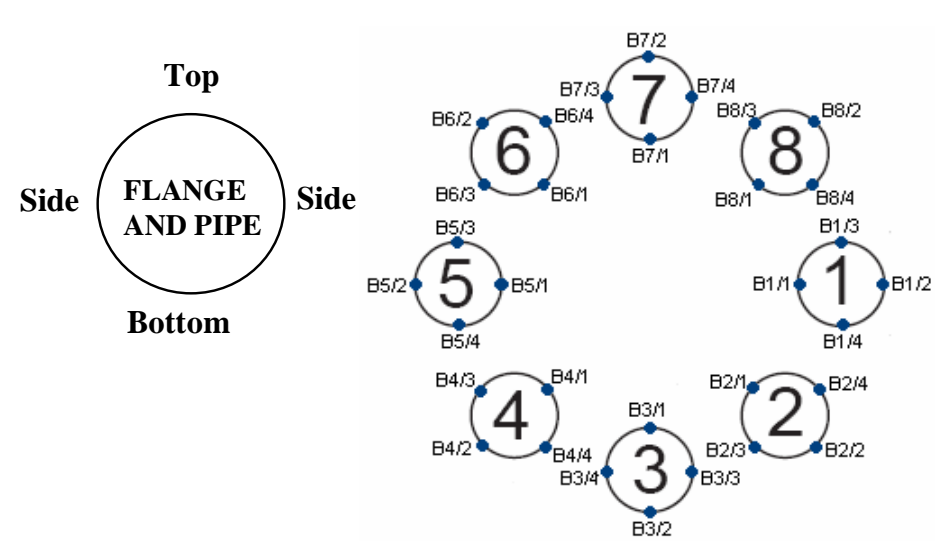

(a)

(b)

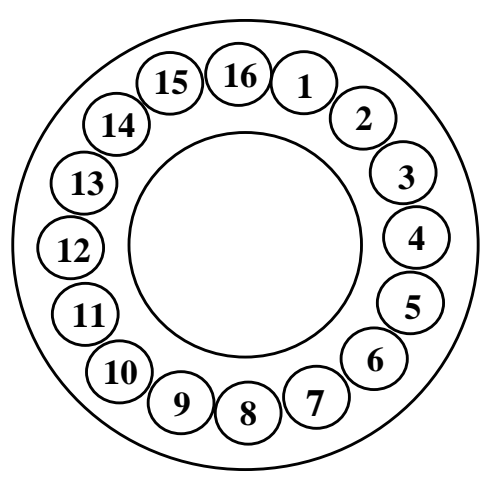

(c)

Fig. 4: Location of strains measured on (a) flange and pipe, (b) bolts-GJ, (c) bolts-NGJ.

\subsection{Sealing Capability}

Gasketed Joint: A small gap between the flanges and the gasket-centring ring was observed during the application of combined loading especially during bending. A clip gauge was used at the bottom of the joint to measure the joint opening during the application of combined loading. A small displacement of 0.35-0.4 mm maximum was calculated from the clip gauge readings. No leakage from the assembly-1 during these tests with the loading to proof test pressure of $23 \mathrm{MPa}$ prove its sealing capability, whereas seepage from assembly-2 during tests shows its failure. For the fluid used during experiments seepage was very small but for other fluid like helium or nitrogen gas it may be worst and may need to be replaced or re-made. 
Non-gasketed Joint: At Design Pressure: During test 1, at the internal pressure of 15.3 $\mathrm{MPa}$ and axial load of $180 \mathrm{kN}$, the bending load was increased gradually and the joint was monitored continuously for leak and opening. Just above the bending load of $134 \mathrm{kN}$, a gap of $0.05 \mathrm{~mm}$ was observed at the bottom. At this load, further application of bending was stopped. This load was kept for 10 minutes, and then the test rig was unloaded as per sequence discussed above. No leakage was observed from the joint. During unloading, joint was monitored and at bending plus axial load i.e. after removing the pressure, no gap, no bolt relaxation or elongation was observed after unloading.

During Test 2, keeping an axial of $180 \mathrm{kN}$ and bending load of $134 \mathrm{kN}$, the internal pressure was gradually increased and the joint was monitored for leak and opening. At about $15.3 \mathrm{MPa}$, a gap of $0.05 \mathrm{~mm}$ was observed at the bottom. This load was kept for 10 minutes, and then the test rig was unloaded as per sequence discussed above. However, no leakage was observed from the joint. During unloading, the joint was monitored and at pressure plus axial load i.e. after removing the bending, no gap was observed. After unloading, no gap, no bolt relaxation or elongation was observed.

At Proof Test Pressure: For this combination, same methodology was adopted as was adopted during Test 2 . For both the sequences applied at the load combinations of pressure $23 \mathrm{MPa}$, axial load of $170 \mathrm{kN}$ and bending of $68 \mathrm{kN}$, no leakage, gap, relaxation and bolt elongation was observed.

At Maximum Load Combination: After performing the above set of tests, it was decided to check the joints strength for higher loads and note the amount of joint opening and leakage if any. The sequence of load applied is mentioned above for Test 3. Maintaining the applied axial load of $340 \mathrm{kN}$ and bending load of $103 \mathrm{kN}$, internal pressure was gradually increased to the proof test pressure and the joint behaviour was continuously monitored. For the combined loading of axial and bending, no gap and leakage was observed. At $8 \mathrm{MPa}$, gap opening was observed just started. At $11.5 \mathrm{MPa}$ and $13 \mathrm{MPa}$ gap opening measured was 0.02 and $0.03 \mathrm{~mm}$ respectively and mostly it was at the bottom bolt 5. At $15.3 \mathrm{MPa}$, it was noted just starting for the bolts 4, 6, 7 and 8 which are on the lower half of the joint, and the feeler gauge was observed to go up-to the bolts. At $23 \mathrm{MPa}$ it was measured $0.07 \mathrm{~mm}$ on the side bolt 8 , with increase gap of 2 to $3 \mathrm{~mm}$ at the bottom. The feeler gauge was observed going in up-to half of the flange joint. Important to note is that no leakage was observed from the joint. This load combination was kept for 2 minute and then the pressure was dropped to zero. A gap of $0.05 \mathrm{~mm}$ was still observed for bolt 5 and 6 at the bottom with gap just closed for bolt 7. After the removal of bending load, no gap was observed from the joint. After unloading the test rig from all the loading, the bolts were checked for relaxation and elongation. The bolt 5 at the very bottom was observed slightly relaxed with no visible elongation.

\subsection{Joint Relaxation}

Gasketed Joint: A negligible small rotation was observed during all the tests. Relaxation was not measured after each set of test but was measured after the completion of all the tests during dismantling. Relaxation in some of the bolts was observed. 
Non-gasketed Joint: During unloading, all the joint assemblies were monitored and no bolt relaxation or bolt elongation was observed after unloading from any of the assembly. Joint opening during the application of combined loading is presented in Fig.5a for the location of bolts 3, 4and 5 at the bottom and in Fig.5b for the location of bolt 8 on sides, However no seepage or leakage was observed from this joint assembly.

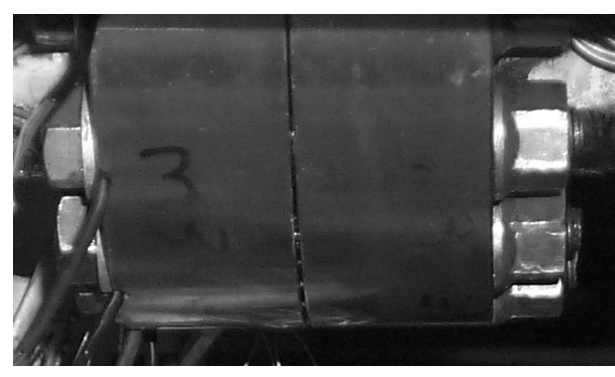

(a)

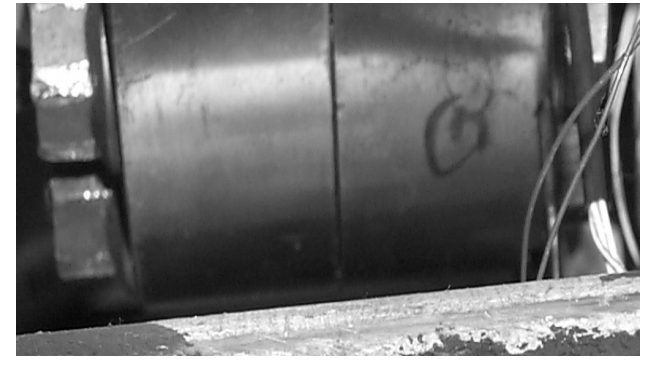

(b)

Fig. 5: NGJ: Gap or joint opening during the application of combined loading at: (a) bottom, (b) along bolt 8 .

\subsection{Joint Strength}

\subsubsection{Stresses and Strains in Flange and Pipe}

Gasketed Joint: Maximum stresses variation calculated from measured strains under bolt up and different combined operating conditions are plotted in Fig. 6a-d. At pipe and hub centre, axial and hoop stresses, calculated from the strains are less than the allowable stress of the pipe and flange material for all the applied loading conditions and are plotted in Fig. $6 \mathrm{a}$ and $6 \mathrm{~b}$ respectively. Axial stress variation at hub-flange fillet for one half is more than the yield of the material whereas for the other half it is less than the yield stress but more than the allowable stress of the material. The stresses are higher for the cases in which the axial load is higher than the bending. All hoop stresses are less than the allowable stresses. Results at hub-flange fillet are plotted in Fig. 6c. At hub-pipe fillet, stress are observed close to the allowable stress for maximum load case and on one location at the top, the stress calculated is more than the yield value. Results are plotted in Fig. 6d. Strain results plotted are only for the different operating conditions and do not include strains produced during bolt up. Strain results for each load stage for flange and the pipe section during loading only for the operating condition only are plotted in Fig. 8ad. Linear elastic strains for all the locations on the flange and pipe section during loading and unloading are observed, concluding no yielding. 

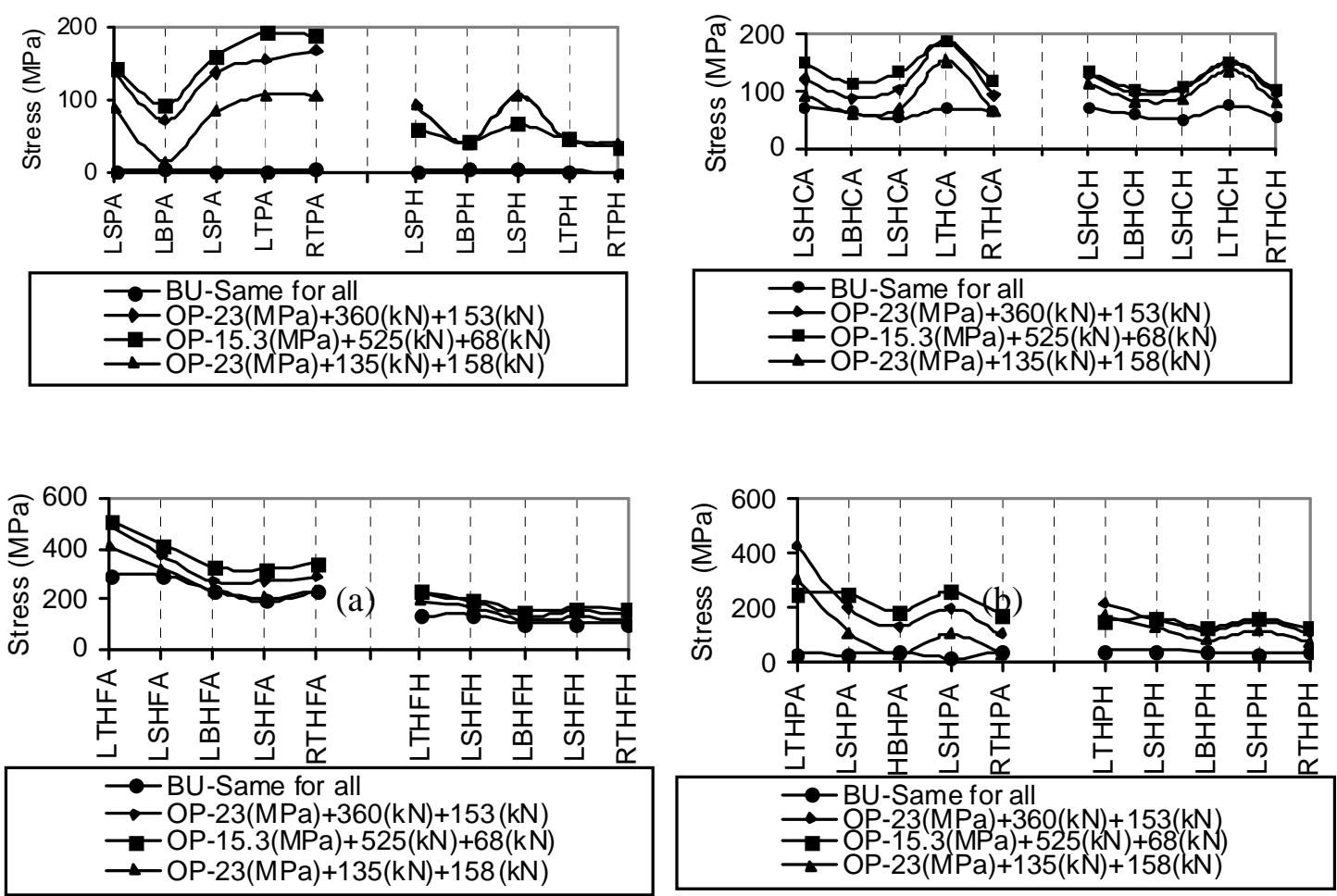

(c)

(d)

Fig. 6: GJ: Stress variation at: (a) Pipe, (b) Hub Centre, (c) Hub Flange Fillet, (d) Hub Pipe Fillet under bolt up and combined operating conditions.

Non-gasketed Joint: Maximum stress variation calculated from the measured strains under bolt up and different operating conditions are discussed for different locations. At hub centre, stresses calculated from strains are different for different locations. Axial stress is the maximum at top location and is more than the allowable and the yield of the flange material. Similarly, the hoop stresses at top location are also more than allowable but are less than the yield of the flange material. Along other locations, these are less than the allowable. Stress pattern around the flange is obvious for all the locations i.e. at top, bottom and sides. Results are plotted in Fig. 7a. At pipe centre the axial and hoop stresses, calculated from the strains are less than the allowable of the pipe material for all the applied loading conditions. Stress results are plotted in Fig. 7b. At hub-flange fillet, stresses calculated are within the allowable for the test 1 and test 2, whereas the stresses for the maximum applied loading was more than the allowable but was less than the yield of the flange material. However, taking account of stress concentration factor for the hubflange fillet the stresses calculated are less than the allowable. Results are plotted in Fig. $7 \mathrm{c}$. 


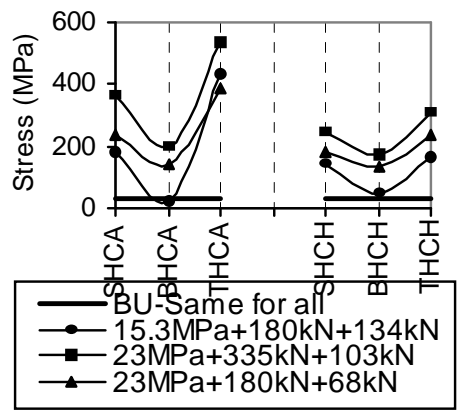

(a)
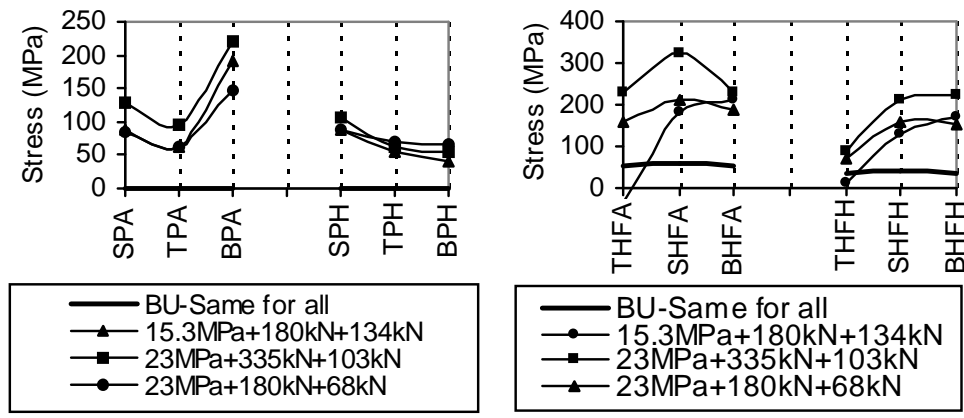

- BU-Same for all

- $15.3 \mathrm{MPa}+180 \mathrm{kN}+134 \mathrm{kN}$ $\rightarrow-23 \mathrm{MPa}+335 \mathrm{kN}+103 \mathrm{kN}$ $\rightarrow 23 \mathrm{MPa}+180 \mathrm{kN}+68 \mathrm{kN}$

Fig. 7: NGJ: Stress Variation under applied loading at: (a) Hub Centre, (b) Pipe, (c) Hub-Flange Fillet.
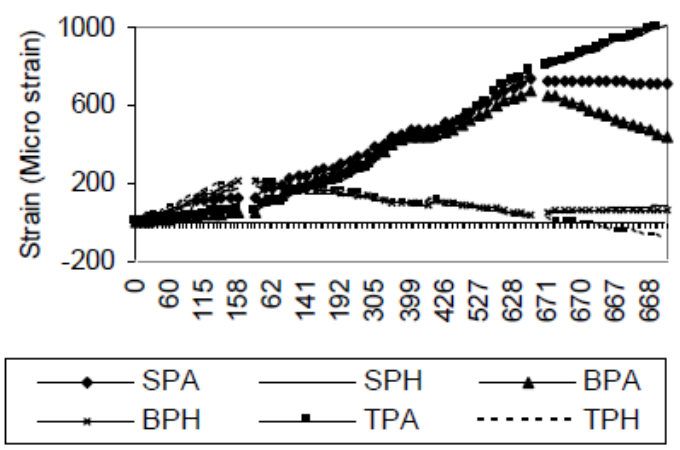

(a)

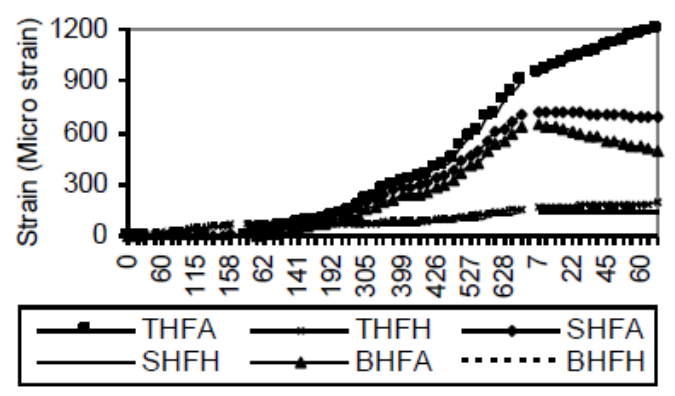

(c)

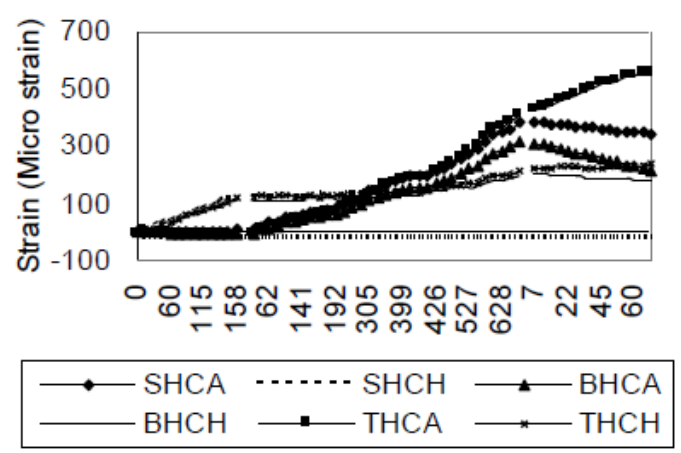

(b)

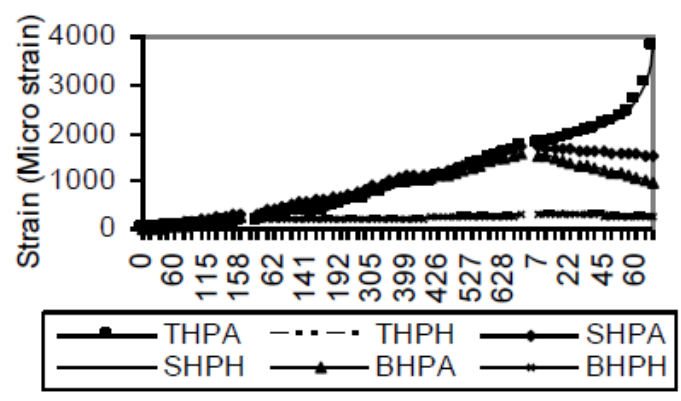

(d)

Fig. 8: GJ: Strain variation at: (a) Pipe, (b) Hub Centre, (c) Hub Flange Fillet, (d) Hub Pipe Fillet during operating conditions only i.e. (Internal pressure (15.3MPa) + Axial Load $(525 \mathrm{kN})+$ Bending Load $(68 \mathrm{kN})$. 
Strain results plotted are only for the different operating conditions and do not include strains produced during bolt up. Strain results for each load stage at flange hub centre are plotted in Fig. 9a-b, at hub-flange fillet in Fig.10a-b and at pipe section in Fig.11a-b under two combined loading conditions. Linear elastic strains for all the locations on the flange and pipe section during loading and unloading are observed, concluding no yielding.

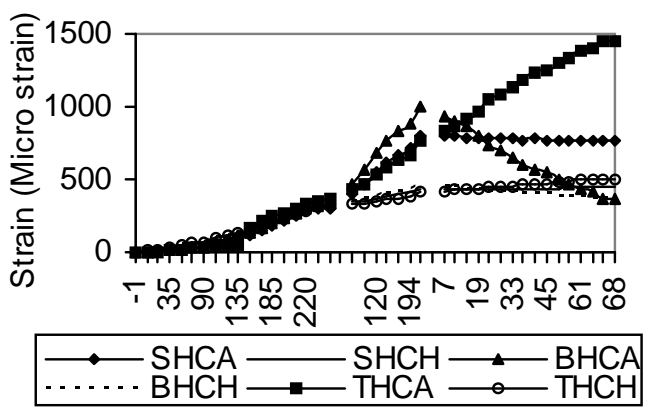

(a)

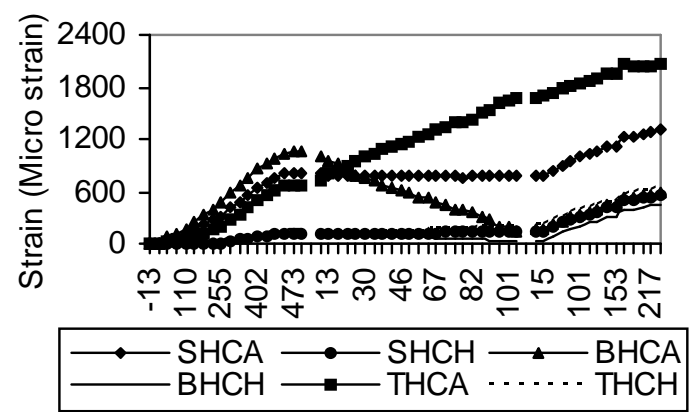

(b)

Fig. 9: NGJ: Strain variation at Hub Centre during loading only at load combination: (a) $23 \mathrm{MPa}+180 \mathrm{kN}+68 \mathrm{kN}$, (b) $335 \mathrm{kN}+103 \mathrm{kN}+23 \mathrm{MPa}$.

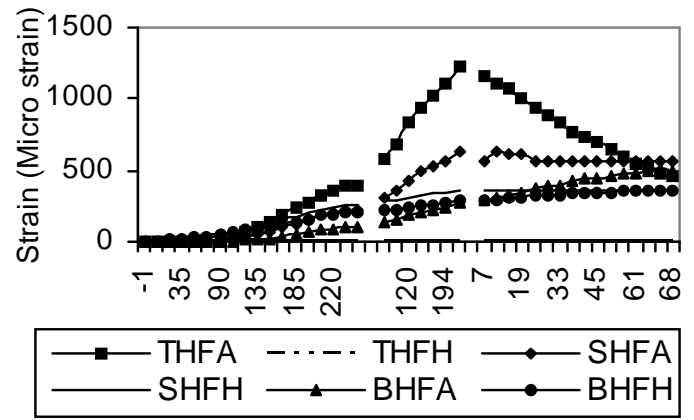

(a)

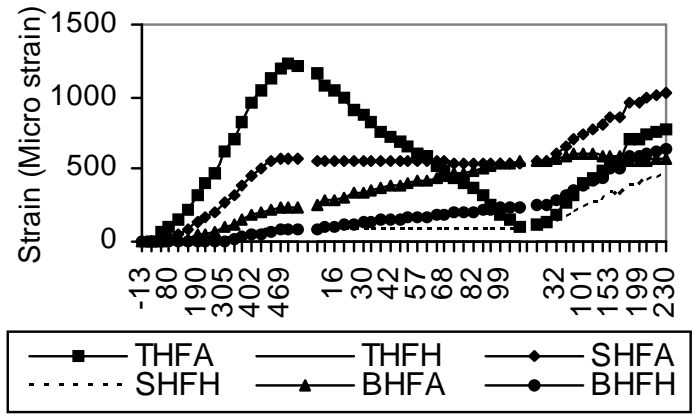

(b)

Fig. 10: NGJ: Strain variation at Hub Flange Fillet during loading only at load combination: (a) $23 \mathrm{MPa}+180 \mathrm{kN}+68 \mathrm{kN}$, (b) $335 \mathrm{kN}+103 \mathrm{kN}+23 \mathrm{MPa}$.

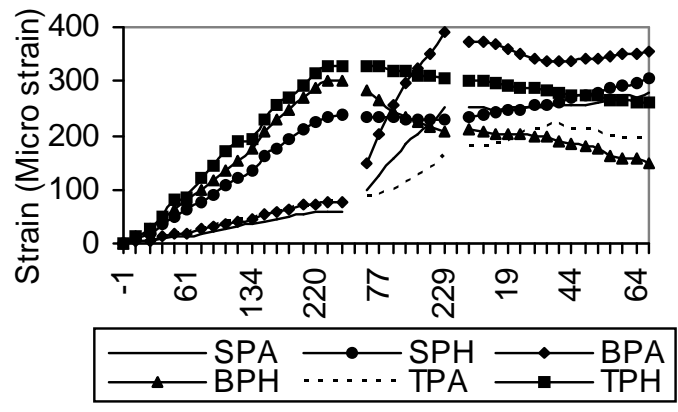

(a)

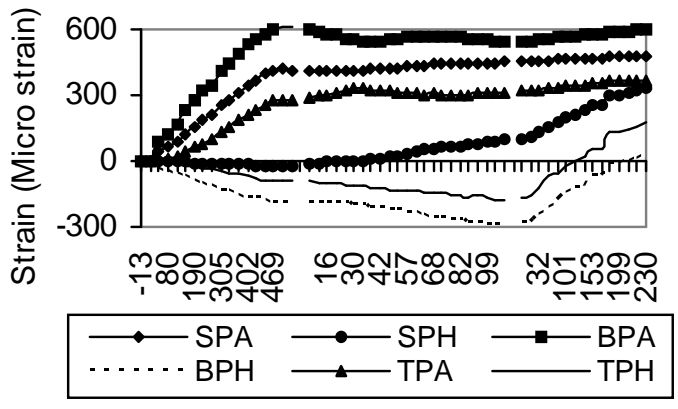

(b) 
Fig. 11: NGJ: Strain variation at Pipe during loading only at load combination: (a) $23 \mathrm{MPa}+180 \mathrm{kN}+68 \mathrm{kN}$, (b) $335 \mathrm{kN}+103 \mathrm{kN}+23 \mathrm{MPa}$.

\subsubsection{Stresses and Strains in Bolts}

Gasketed Joint: Stress variation for all the bolts in the gasketed joint during bolt up and different operating condition is obvious from the individual gauges as well as from the average stress of all the bolts and is plotted in Fig. 12. However, maximum stress in the bolt observed is less than the yield stress of the bolt material. Strain results plotted are only for the different operating conditions and do not include strains produced during bolt up. Strain variation for all the 8 bolts along four locations at 90 degree i.e. top, bottom and sides in the joint and are plotted in Fig. 13. Strain variation showing bolt bending during bolt up is discussed in detail by Abid in $[4,25,26]$.

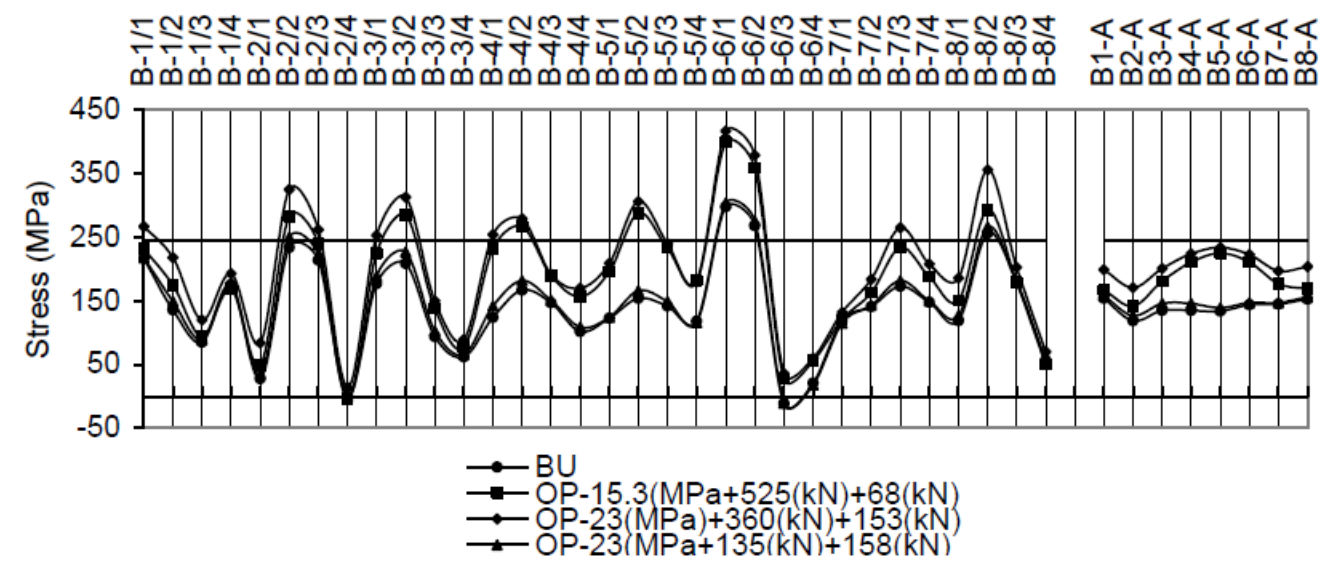

Fig. 12: GJ: Bolt stress variation under bolt up and combined operating conditions. 


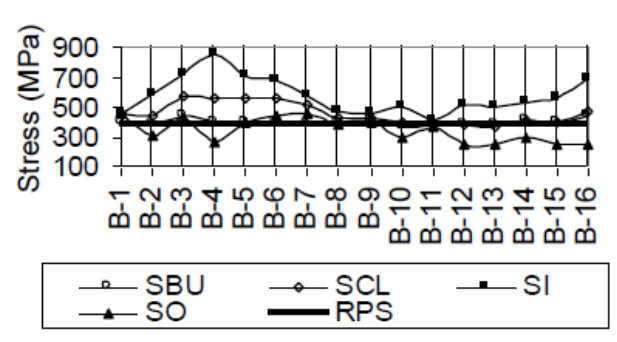

(a)

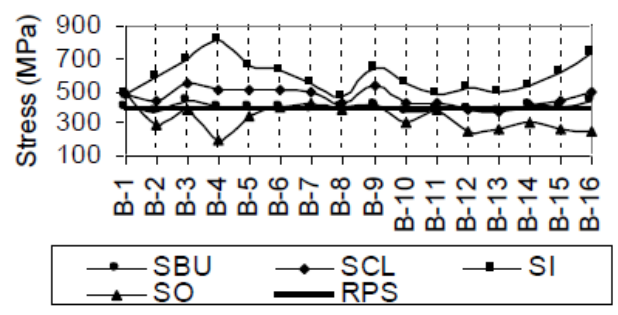

(c)

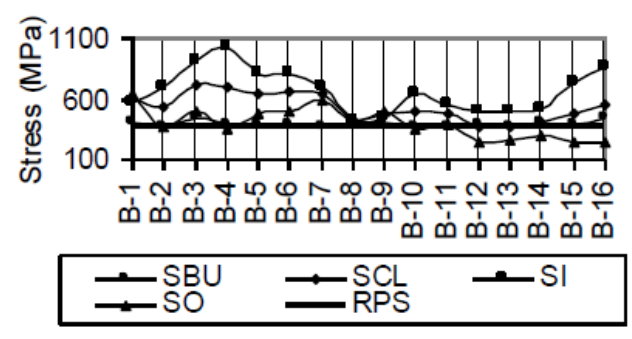

(b)

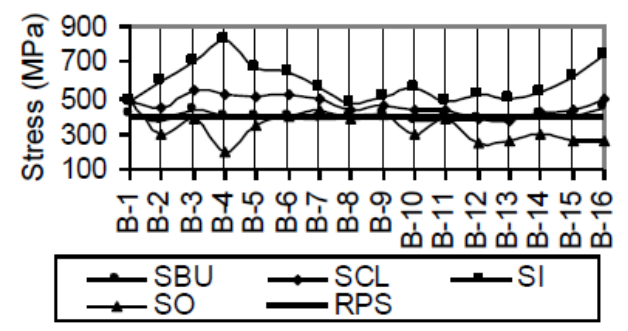

(d)

Fig. 13: GJ: Bolt stress variation at load combination: (a) $15.3 \mathrm{MPa}+180 \mathrm{kN}+134 \mathrm{kN}$, (b) $335 \mathrm{kN}+103 \mathrm{kN}+23 \mathrm{MPa}$, (c) $23 \mathrm{MPa}+180 \mathrm{kN}+68 \mathrm{kN}$, (d) $180 \mathrm{kN}+68 \mathrm{kN}+23 \mathrm{MPa}$.

Non-gasketed Joint: Stress variation for all the bolts in non-gasketed joint during bolt up and different operating conditions is obvious from the individual gauges as well as from the average stress of all the bolts and is plotted in Fig.13a-d for different combined loading and in different loading sequences.

Higher stress in bolt 4 was noted due to bad connection of the strain gauge. For test 1 and test 2, stress results for all the bolts are almost the same. The average stresses calculated during operating condition are within the allowable and are the same for the lower half of the joint. However, the stresses in the inside gauge of bolt 3, 4, 5 and 6 were found more than the allowable and the joint opening was observed at the bottom. At the maximum applied loads during test 3, the average stress calculated for the bolts 3 to bolt 7 in the lower half is close to the yield of the bolt. For the bolts in the upper half, the stress difference is small. This shows the yielding of the bolts, but the bolts were found in good condition. This shows that the bolts can take higher load than the mentioned in the code. Bending of the bolt is obvious for almost all the bolts from the inside and outside gauge readings, which is due to the eccentric as well as the bending loading in the joint.

Strain results plotted are only for the different operating conditions and do not include strains produced during bolt up. Strain variation for all the 16 bolts along four locations at 180 degree in the joint and are plotted in Fig. 15a-d for different combined loading and different loading sequences. 

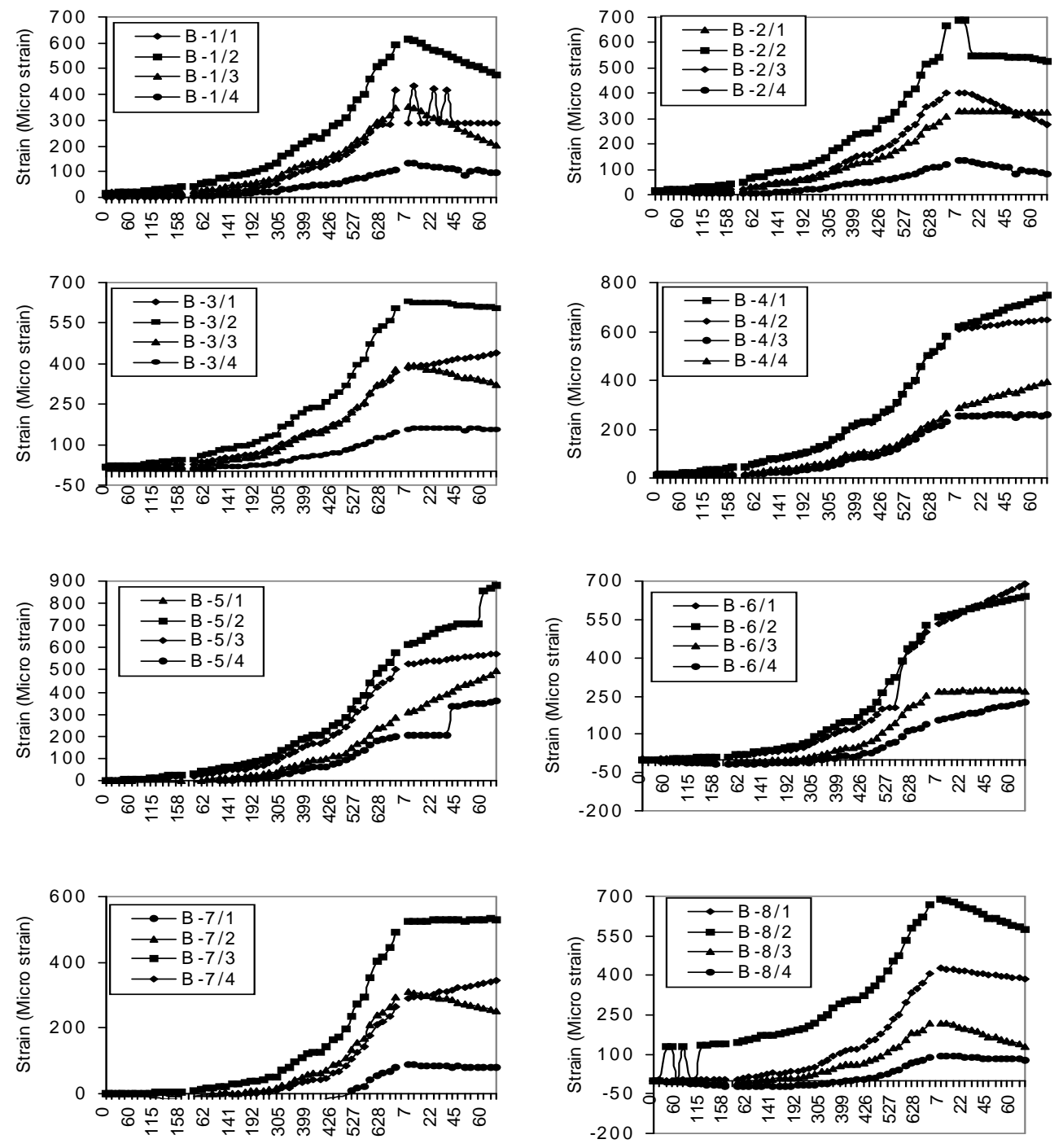

Fig. 14: GJ: Strain in Bolts during loading only under operating conditions only i.e. (Internal pressure $(15.3 \mathrm{MPa})+$ Axial Load $(525 \mathrm{kN})+$ Bending Load $(68 \mathrm{kN})$. 


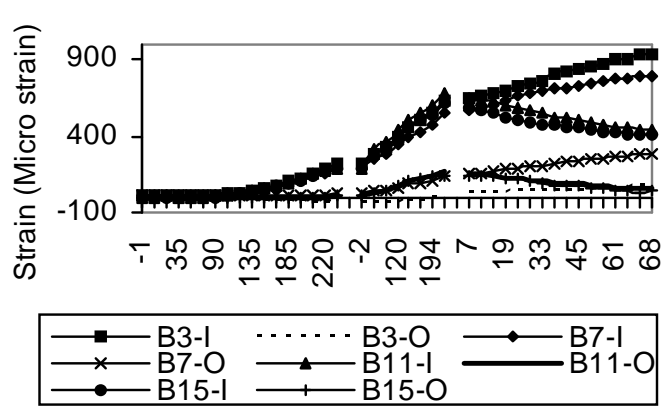

(a)

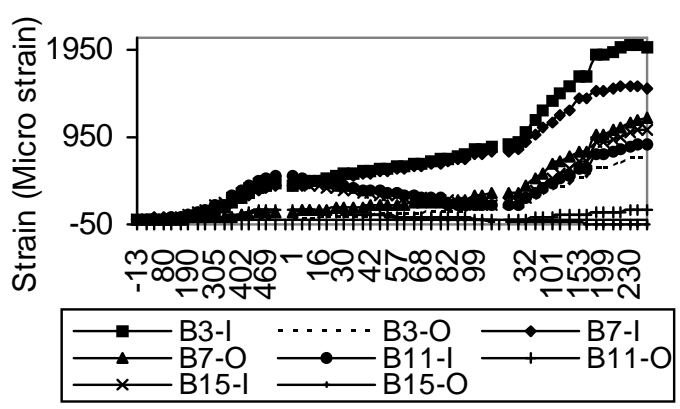

(c)
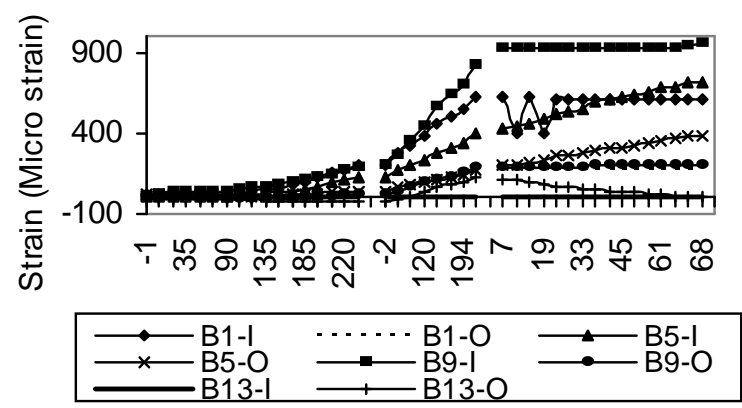

(b)

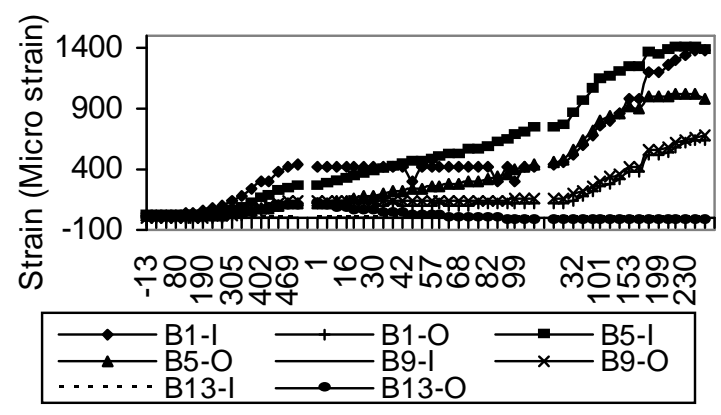

(d)

Fig. 15: NGJ: Strain variation in Bolts during loading only at load combination: (a-b) $23 \mathrm{MPa}+180 \mathrm{kN}+68 \mathrm{kN}$, (c-d) $335 \mathrm{kN}+103 \mathrm{kN}+23 \mathrm{MPa}$.

\section{COMPARISON WITH EQUIVALENT PRESSURE APPROACH}

The applied axial or bending load can be calculated in terms of equivalent pressure applied in the pipe or vessel based on the longitudinal stress as per equivalent pressure approach given in [4]. Equivalent pressure is calculated and results are given in Table 1 and are compared with the allowable stress of pipe material. Using equivalent pressure approach, equivalent pressure calculated is much higher than the design and proof test pressures.

Longitudinal stress due to a direct load, $\mathrm{W}$ :

$$
\sigma_{l}=\frac{p_{e} D}{4 t}=\frac{W}{\pi D t}
$$

Where $D$ is mean diameter of pipe and $t$ is the pipe thickness.

Equivalent pressure $\left(P_{e}\right)$

$$
p_{e}=\frac{4 W}{\pi D^{2}}
$$

Longitudinal stress due to a moment load, M: $\quad \sigma_{l}=\frac{p_{e} D}{4 t}=\frac{4 M}{\pi D^{2} t}$ 
Equivalent pressure $\left(P_{e}\right)$

$$
p_{e}=\frac{16 M}{\pi D^{3}}
$$

Table 1: Calculation of equal and total pressure using 'equivalent pressure approach' under combined loading.

\begin{tabular}{|c|c|c|c|c|c|c|c|c|c|c|c|c|}
\hline $\mathbf{F}$ & $\mathbf{P}$ & $\mathbf{M}$ & Pe-F & Pe-M & $\mathbf{T P}$ & \multicolumn{2}{|c|}{ More than } & \multicolumn{5}{|c|}{$\begin{array}{l}\text { Longitudinal Stress at Pipe } \\
\text { section under (MPa) }\end{array}$} \\
\hline \multirow{3}{*}{$\mathbf{k N}$} & & & & & & DP & PTP & $\mathbf{P}$ & $\mathbf{F}$ & $\mathbf{M}$ & & $\mathbf{L}$ \\
\hline & MPa & kNm & MPa & MPa & MPa & MPa & MPa & & & & Cal & Exp \\
\hline & \multicolumn{12}{|c|}{ GASKETED JOINT } \\
\hline 525 & 15.3 & 9 & 66 & 44 & 125 & 8.2 & 5.4 & 21 & 123 & 82 & 226 & 155 \\
\hline 135 & 15.3 & 21 & 17 & 102 & 134 & 8.8 & 5.8 & 21 & 32 & 191 & 244 & 130 \\
\hline 135 & 23.0 & 21 & 17 & 102 & 142 & 9.3 & 6.2 & 32 & 32 & 191 & 254 & 101 \\
\hline 360 & 23.0 & 20 & 45 & 101 & 169 & 11.0 & 7.3 & 32 & 84 & 188 & 305 & 135 \\
\hline \multicolumn{13}{|c|}{ NON-GASKETED JOINT } \\
\hline 173 & 15.3 & 20 & 22 & 101 & 138 & 9.0 & 6.0 & 21 & 40 & 188 & 250 & 88 \\
\hline 180 & 15.3 & 17 & 23 & 87 & 124 & 8.1 & 5.4 & 21 & 42 & 162 & 225 & 91 \\
\hline 173 & 23.0 & 12 & 22 & 58 & 103 & 6.7 & 4.5 & 32 & 40 & 109 & 181 & 88 \\
\hline 180 & 23.0 & 9 & 23 & 44 & 90 & 5.9 & 3.9 & 32 & 42 & 82 & 156 & 90 \\
\hline 335 & 23.0 & 13 & 42 & 67 & 132 & 8.6 & 5.7 & 32 & 78 & 124 & 235 & 130 \\
\hline
\end{tabular}

For applied axial load equal to the pre-load in the joint, equivalent pressure calculated was about 4 times and 2.6 times the permissible and proof test pressures respectively. For the non-gasketed joint a maximum axial load of $664 \mathrm{kN}$, applied was about 5.5 times and 3.6 times the permissible and proof test pressures respectively. For the different applied bending load, equivalent pressure was calculated about 4 to 6.5 times and 2.6 to 4.4 times the design and proof test pressures. For combined load conditions due to the added effect, higher values of equivalent pressures up to about 10 times the maximum permissible working pressure were observed.

Longitudinal stress for all internal pressure, axial and bending load were calculated separately and added. It is important to note that the calculated stress was less than the allowable stress under applied combined loading, whereas equivalent pressure calculated showing much higher pressures. 
Longitudinal stress for all internal pressure, axial and bending load were calculated separately and added. It is important to note that the calculated stress was less than the allowable stress under applied combined loading, whereas equivalent pressure calculated showing much higher pressures.

In the light of results and discussion, it is concluded that the equivalent pressure approach can not be directly applied for all the load cases for the bolted joints. From the longitudinal stress calculated, it can be applied only for internal pressure and axial load cases singly or in combination. For the load cases, which involve bending, this theory gives much higher stresses, whereas experimental results are found conservative. Equivalent pressure might be appropriate for the case of the continuous vessel or pipe during bending but it can not be related to bending load application due to the load shared by the flanges and bolts. In case of gasketed joint due to the presence of gasket interaction of different components behaves differently. However, in terms of equivalent pressure values, it is not straightforward to use these pressures and such additional pressure loads should be treated with care. In-spite of all these higher equivalent pressures, from experiments, however, joint strength and sealing capability of both the joints is proved.

\section{DETERMINATION OF JOINT LOAD CAPACITY USING SUPERPOSITION OF LOADS}

For the combined load application a simple relationship derived in [4] is used here to optimize the joint load capacity for the successful working of the joint as given in equation-7;

$$
\frac{F}{F_{\text {Max }}}+\frac{P}{P_{\text {Max }}}+\frac{M}{M_{\text {Max }}} \leq 1
$$

Based on actual applied and maximum permissible calculated loads, results of all the assemblies tested are summarized in Table 2. Load capacities calculated are based on three internal pressure loads i.e. design (15.3 MPa), proof test (23 MPa) and maximum applied pressure (40 MPa). During experiments higher loads than the calculated were applied to observe joint behavior. However, in the light of results and observations joint load capacity can be optimized for exact selection and successful working of the joint. Therefore, joint capacity for the axial load is based on the pre-load applied in the joints. For the bending loading, it is based on the calculated value considering the pipe simply supported on two saddles and for four point bending. From the applied loads, it is concluded that the joints can take much higher load than the defined in different international codes for internal pressure only. In addition, it is also proved that the joints can also take much higher other external loads in additional to the internal pressure loading. 
Table 2: Load carrying capacities of the GJ and NGJ under combined loading.

\begin{tabular}{|c|c|c|c|c|c|c|c|c|c|c|}
\hline $\mathbf{F}$ & $\mathbf{P}$ & $\mathbf{M}$ & $\mathbf{F}_{\max }$ & $\mathbf{P}_{\max }$ & $\mathbf{M}_{\max }$ & $\mathbf{F} / \mathbf{F}_{\max }$ & $\mathbf{P} / \mathbf{P}_{\max }$ & $\mathbf{M} / \mathbf{M}_{\max }$ & $\begin{array}{l}\mathbf{F} / \mathbf{F}_{\text {max }}+ \\
\mathbf{P} / \mathbf{P}_{\text {max }}+ \\
M / \mathbf{M}_{\text {max }}\end{array}$ & $\begin{array}{l}\text { Extra } \\
\text { Load } \\
\text { applied }\end{array}$ \\
\hline $\mathbf{k N}$ & MPa & $\mathbf{k N m}$ & $\mathbf{k N}$ & MPa & kNm & & & & & $(\%)$ \\
\hline \multicolumn{11}{|c|}{ GASKETED JOINT } \\
\hline 525 & 15.3 & 8.84 & 388 & 40 & 12.44 & 1.35 & 0.38 & 0.71 & 2.45 & 145 \\
\hline 135 & 15.3 & 20.54 & 388 & 40 & 12.44 & 0.35 & 0.38 & 1.65 & 2.38 & 138 \\
\hline 135 & 23.0 & 20.54 & 342 & 40 & 12.09 & 0.39 & 0.58 & 1.70 & 2.67 & 167 \\
\hline 360 & 23.0 & 20.28 & 342 & 40 & 12.09 & 1.05 & 0.58 & 1.68 & 3.31 & 231 \\
\hline \multicolumn{11}{|c|}{ NON-GASKETED JOINT } \\
\hline 173 & 15.3 & 20.28 & 388 & 40 & 12.44 & 0.45 & 0.38 & 1.63 & 2.46 & 146 \\
\hline 180 & 15.3 & 17.42 & 388 & 40 & 12.44 & 0.46 & 0.38 & 1.40 & 2.25 & 125 \\
\hline 173 & 23.0 & 11.7 & 342 & 40 & 12.09 & 0.51 & 1.00 & 0.97 & 2.47 & 147 \\
\hline 180 & 23.0 & 8.84 & 342 & 40 & 12.09 & 0.53 & 1.00 & 0.73 & 2.26 & 126 \\
\hline 335 & 23.0 & 13.39 & 342 & 40 & 12.09 & 0.98 & 1.00 & 1.11 & 3.09 & 209 \\
\hline
\end{tabular}

\section{CONCLUSIONS}

- Flange joint assemblies i.e. gasketed and non gasketed of 4 inch size, ANSI Class 900\# are made and tested under different loading/operating conditions and their comparative performance is discussed for strength and sealing.

- Overall, from the behaviour of the gasketed joints it is proved that this can be an excellent assembly, if it is made properly with great care. Regarding sealing capability, seepage was noted from one of the joint assembly showing its failure, although the magnitude noted was very small.

- After all the tests, during dismantling, relaxation is noted from all the bolts of each gasketed joint assembly. It is important to note that all these experiments have been performed in a static or lab environment but for the conditions where vibrations are present it cannot be guaranteed especially for the gasketed joint, where during the preloading a stress variation cannot be controlled.

- Overall during combined loading, no seepage/leakage and no yielding of the nongasketed joint assembly with seal rings inside proved its safe strength and sealing capability. In addition, due to the static mode observed in the joint no fatigue behaviour is concluded resulting in no possibility of relaxation of bolts in the joint.

- Regarding sealing, even with the gap at the bottom of about 2-3mm; the joint was proved leak proof. The gap was also felt up-to the half of the depth of the flange joint using feeler gauge of $0.05 \mathrm{~mm}$.

- The loads at which the joint opening was observed were regarded as the maximum load to be applied in the joint for no leak condition. It is also subjected to the condition 
that the joint is made properly with properly pre-loaded good quality bolts, using the seal ring inside the joint.

- It is concluded that the non-gasketed joint can take much higher load than the defined in different international codes for internal pressure only.

- It is concluded that both the gasketed and non-gasketed joints can take much higher load than the defined in different international codes for internal pressure only. It is also proved that the joints can also take much higher other external loads in additional to the internal pressure loading regarding its strength, however sealing is the most important parameter to be ensured for its safe performance.

- It is concluded that the equivalent pressure approach cannot be directly applied for in the case of combined load application for both the gasketed and non-gasketed joints.

- Load capacities calculated are based on three internal pressure loads i.e. design $(15.3 \mathrm{MPa})$, proof test $(23 \mathrm{MPa})$ and maximum applied pressure (40MPa). During experiments higher loads than the calculated were applied to observe joint behavior. However, in the light of results and observations joint load capacity can be optimized for exact selection and successful working of the joint.

- Therefore, joint capacity for the axial load is based on the pre-load applied in the joints. For the bending loading, it is based on the calculated value considering the pipe simply supported on two saddles and for four point bending.

- Finally, the methodology and relationships proposed can be used as a simple approach for calculating load capacity of both the joints.

\section{REFERENCES}

[1] BS 1560. (1989). Steel Pipe Flanges for the Petroleum Industry. British Standards Institution, London, UK.

[2] ASME Boiler and Pressure Vessel Code, Section VIII, (1998). American Society of Mech. Eng., New York, USA.

[3] Abid, M., Nash, D. H. Comparative study of the behaviour of conventional gasketed and compact non-gasketed flanged pipe joints under bolt up and operating conditions. International Journal of Pressure Vessels and Piping, 80, 831-841, 2004.

[4] Abid, M., Experimental and Analytical studies of conventional (gasketed) and unconventional (non gasketed) flanged pipe joints (with special emphasis on the engineering of 'joint strength' and 'sealing'”. PhD Thesis. University of Strathclyde, Glasgow, UK, 2000.

[5] Webjörn, J., Flange Design in Sweden. Petrochemical Mechanical Engineering Conference, American Society of Mechanical Engineers, Philadelphia, USA. 17-20, 1967.

[6] Webjörn, J. (1985). The Bolted Joint - a Series of Problems. Linköping Studies in Science and Technology, Dissertation No. 130.

[7] Abid, M., Nash, D. H., Webjörn, J., The stamina of non-gasketed flanges. Fatigue2000, Cambridge, 575-584, 2000.

[8] Abid, M., Nash, D. H., A parametric study of metal-to-metal contact flanges with optimised geometry for safe stress and no-leak conditions. International Journal of Pressure Vessels and Piping, (81), 67-74, 2004. 
[9] Abid, M., Determination of safe operating conditions for non-gasketed flange joint under combined internal pressure and temperature. International Journal of Mechanics and Materials in Design. vol. 2: 129-140, 2005

[10] Abid, M., Design and Analysis of Non-Gasketed Bolted Flanged Pipe Joint Under Combined Internal Pressure and Temperature Loading. $3^{\text {rd }}$ BSME-ASME International Conference on Thermal Engineering, Dhaka Bangladesh. 20-22 December, 2006, pp. 1-11.

[11] Bouzid, A.H., Derenne, Michel., Chaarani, Abbas., Tightness Prediction of Bolted Flanged Connections Subjected to External Bending Moments. PVP Am. Soc. Mech. Eng. (367), pp 61-67, 1998.

[12] Sawa, T., Shimizu, A., A Stress Analysis of Pipe Flange Connections Subjected to External Bending Momen”. PVP Am. Soc. Mech. Eng., (405), pp 85-94, 2000.

[13] Sawa, T., Matsumoto, M., FEM Stress Analysis and Sealing Performance in Pipe Flange Connections with Gaskets Subjected to Internal Pressure and External Bending Moment. PVP Am. Soc. Mech. Eng., (433), pp 81-89, 2002.

[14] Sawa, T., Maezaki, W., Nagata, S., Stress Analysis and Sealing Performance Evaluation of Pipe Flange Connections with Gaskets Subjected to Internal Pressure and External Bending Moment (Effect of Scatter in Bolt Preload). PVP Am. Soc. Mech. Eng. (478), pp 137-143, 2004.

[15] Sawa, T., Matsumoto, M., Ando, F., FEM Stress Analysis and Sealing Performance in Pipe Flange Connections with Gaskets Subjected to External Bending Moment (Case where Internal Fluid is Liquid). PVP Am. Soc. Mech. Eng., (457), pp 85-95, 2003.

[16] Cao, J., Bell, A. J., Elastic Analysis of a Circular Flange Joint Subjected to Axial Force. Int. J. of Pressure Vessels and Piping (55), pp 435-449, 1993.

[17] Koves, W. J., Design for leakage in flange joints under external loads" ASME J. Pressure Vessels Technology. 129(2), pp. 334-337, 2007.

[18] PrEN13445-3. (1999), Annex-G (Normative), Alternative Design rules for flanges and gasketed flange connections.

[19] ASME/ANSI B16.5, (1998), Pipe Flanges and Flanged Fittings, Sec VIII, Div. I.

[20] ASME Boiler and Pressure Vessel Code, Section II, part D, (2001), American Society of Mechanical Engineers, New York.

[21] BS 3692 (1967), Specification for ISO metric precision hexagonal bolts, screws and nuts.

[22] PD 5500 (2007), Unfired Fusion Welded Pressure Vessels, British Standards Institution, London.

[23] ES/090 Rev: 1, Design and Engineering Practices, DEP 31.38.01.15.Gen (Piping Class Exploration and Production).

[24] John Spence and A. S. Tooth, Pressure Vessel Design- Concepts and Principals, (ISBN 0 419 19080 5)

[25] Abid, M., Nash, D.H., Relaxation behaviour of a gasketed and non-gasketed bolted flanged pipe joint - A Comparative Study. WSEAS Transactions on Applied and Theoretical Mechanics'. Issue-2, vol. 1 (2006). pp. 239-246.

[26] Abid, M., Nash, D.H. Joint relaxation behaviour of gasketed bolted flanged pipe joint during joint assembly. 2nd WSEAS International Conference on Applied and Theoretical Mechanics (MECHANICS'06) TTVenice, Italy, November 20-22, 2006. pp. 319-325. 


\section{NOMENCLATURE}

\begin{tabular}{|c|c|c|}
\hline$v$ & Poisson's ratio & \\
\hline E & Young's modulus of elasticity & $\mathrm{MPa}$ \\
\hline$R$ & Strain gauge reading on the right side of the joint & $\mu \epsilon$ \\
\hline$L$ & Strain gauge reading on the left side of the joint & $\mu \epsilon$ \\
\hline$S$ & Strain gauge reading along side location & $\mu \epsilon$ \\
\hline$B$ & Strain gauge reading along bottom location & $\mu \epsilon$ \\
\hline$T$ & Strain gauge reading along top location & $\mu \epsilon$ \\
\hline$H$ & Hoop stress & $\mathrm{MPa}$ \\
\hline$A$ & Axial Stress & $\mathrm{MPa}$ \\
\hline$D P$ & Design pressure & $15.3 \mathrm{MPa}$ \\
\hline$P T$ & Proof test pressure & $23 \mathrm{MPa}$ \\
\hline$H C$ & Hub centre & \\
\hline$H F$ & Hub flange fillet & \\
\hline$P$ & Pipe & \\
\hline$O P$ & Operating conditions & \\
\hline$B U$ & Bolt Up & \\
\hline$I$ & Inside gauge & \\
\hline$O$ & Outside gauge & \\
\hline$F$ & Actual axial load applied & $\mathrm{kN}$ \\
\hline$M$ & Actual bending moment applied & $\mathrm{kN}$ \\
\hline$P$ & Actual required fluid pressure applied & $\mathrm{MPa}$ \\
\hline$F_{\max }$ & Maximum axial load permissible & $\mathrm{k}$ \\
\hline$M_{\max }$ & Maximum bending moment permissible & $\mathrm{kN}$ \\
\hline$P_{\max }$ & Maximum fluid pressure permissible & $\mathrm{MPa}$ \\
\hline$P e$ & Equivalent pressure & $\mathrm{MPa}$ \\
\hline$T P$ & Total pressure & $\mathrm{MPa}$ \\
\hline$C L$ & Combined loadin & \\
\hline
\end{tabular}

